\title{
Single-prolonged stress induces increased phosphorylation of extracellular signal-regulated kinase in a rat model of post-traumatic stress disorder
}

\author{
BING XIAO $^{1,2}$, FANG HAN ${ }^{1,2}$, HAI-TAO WANG ${ }^{1,3}$ and YU-XIU SHI ${ }^{1,2}$ \\ ${ }^{1}$ Department of Histology and Embryology, Basic Medical Sciences College; ${ }^{2}$ Institute of Pathology and Pathophysiology, \\ China Medical University, Shenyang 110001; ${ }^{3}$ Department of Histology and Embryology, \\ North China Coal Medical University, Tangshan 063000, P.R. China
}

Received December 14, 2010; Accepted March 9, 2011

DOI: $10.3892 / \mathrm{mmr} .2011 .459$

\begin{abstract}
The extracellular signal-regulated kinase (ERK) signaling transduction pathway has been implicated in multiple physiological processes. It is not clear whether the ERK1/2 pathway participates in post-traumatic stress disorder (PTSD). The aim of this study was to provide novel insights into the mechanisms of how the amygdala participates in PTSD by investigating changes in the ERK1/2 pathway induced by single prolonged stress (SPS). The level of phosphorylated ERK1/2 (pERK1/2) protein was defined in a single-prolonged stress (SPS) animal model of post-traumatic stress disorder. A total of 100 male Wistar rats were randomly divided into a normal control group and SPS groups of 0, 30, 60 and 120 min. pERK1/2 distribution in the amygdala neurons was observed using immune electron microscopy. The expression of pERK1/2 was examined by immunohistochemistry and Western blotting. The pERK protein was located in some cell organelles, such as the mitochondria and neuraxon. Quantitatively, the expression of pERK protein level was significantly increased in the SPS rats. The results suggest that the ERK signal transduction pathway may play a crucial role in the pathology of PTSD.
\end{abstract}

\section{Introduction}

Post-traumatic stress disorder (PTSD) is an anxiety disorder that develops after exposure to a life-threatening traumatic experience. It is characterized by symptoms that often endure for years, including continuous re-experiencing of the traumatic event, avoidance of stimuli associated with the

Correspondence to: Professor Yu-Xiu Shi, Department of Histology and Embryology, Basic Medical Sciences College, China Medical University, 92 North 2nd Road, Shenyang 110001, P.R. China E-mail: happyice1983@sina.com

Key words: extracellular signal-regulated kinase (ERK), phosphorylated ERK1/2, basolateral amygdala, single-prolonged stress, post-traumatic stress disorder, mechanism trauma, numbing of general responsiveness and increased arousal (1). Single-prolonged stress (SPS) (2) was shown to induce enhanced inhibition of the hypothalamic-pituitaryadrenal axis, which is a putative neuroendocrinological hallmark of PTSD (3-5). Subsequently, SPS paradigms were extensively developed and employed in the investigation of $\operatorname{PTSD}(6,7)$.

As one of the key regions in the limbic system of the brain, the amygdala has been documented to play a crucial role in fear, rage and emotional memory $(8,9)$. Amygdala hyperresponsivity with apparent exaggerated responses in PTSD has been reported (10-19). Cui et al additionally found that behavioral changes in response to SPS may be attributed to the amygdala (20).

Extracellular signal-regulated protein kinases (ERK) are involved in a complex intracellular signaling cascade that controls various neurobiological effects (21). The active form of ERK1/2, namely phosphorylated ERK1/2 protein (pERK1/2), is activated in response to various excitatory stimuli (22) and is crucial for the regulation of the transcription of several transcriptional factors $(21,23)$. The ERK pathway, a highly conserved kinase cascade, mediates the transmission of signals from cell surface receptors to cytoplasmic and nuclear effectors (24). It is well known that ERK1/2 play important roles in numerous types of cells, including neurons. The ERK1/2 pathway is activated by stimuli associated with synaptic activity and plasticity in neurons (25). Several lines of evidence indicate that the ERK1/2 signal pathway is activated by various stimuli (24), including exposure to stress (26). Following neuronal injury, the ERK pathway is activated, suggesting that it plays a role in cell death (27-29). Ding et al hypothesized that cellular apoptosis in the amygdala of rats in a PTSD model may be one of the causes of amygdala atrophy, which may decrease the volume of the amygdala (30). However, whether the ERK1/2 pathway is activated in the amygdala during SPS is not as yet clear. In view of the importance of the ERK pathway, we aimed to examine changes in the level of pERK1/2 in the amygdala of SPS rats, to determine whether ERK is involved in SPS. Our findings provide novel insights into the mechanism of the participation of the amygdala in PTSD. 


\section{Materials and methods}

Experimental animals. The study utilized 100 healthy male Wistar rats, aged 7 or 8 weeks at the start of the experiment and weighing approximately $180 \mathrm{~g}$, supplied by the Animal Experimental Center of China Medical University. The rats were maintained at $22 \pm 1^{\circ} \mathrm{C}$ and $55 \pm 5 \%$ humidity on a 12 -h light/dark cycle with free access to food and water, and were allowed to acclimatize for 1 week prior to the experiments. Experiments were performed in accordance with the National Institute of Health Guidelines for the Care and Use of Laboratory Animals (NIH Publications no. 80-23, revised 1996). All efforts were made to reduce the number of animals used and to minimize animal suffering during the experiment.

Model establishment and grouping. The rats were randomly divided into five groups: the SPS treatment groups $(0,30,60$ and $120 \mathrm{~min}$ ) and the normal control group. The SPS model consisted of $2 \mathrm{~h}$ of whole body restraint in an animal holder, followed by $20 \mathrm{~min}$ of immediate forced swimming (temperature, $25^{\circ} \mathrm{C}$; depth, $40 \mathrm{~cm}$ ). The rats were allowed to recuperate for $15 \mathrm{~min}$, then exposed to ether vapor until loss of consciousness. The rats were then returned to their home cage and left undisturbed until being sacrificed for the experiments. The normal control rats were maintained in their individual home cages with no handling, and were sacrificed after acclimating to their new environment for a week.

Immune electron microscopy. Rats in each group $(\mathrm{n}=5)$ were transcardially infused with $200-300 \mathrm{ml}$ of pre-cold saline through the ascending aorta, followed by $300 \mathrm{ml}$ of $0.01 \mathrm{M}$ PBS (pH 7.4) containing 2\% PFA and $2.5 \%$ glutaraldehyde. The brain was removed and then postfixed overnight. The next day, the amygdala was dissected and cut into small fragments of $\sim 1 \mathrm{~mm}^{3}$, which were postfixed in $1 \%$ osmium tetroxide for $1 \mathrm{~h}$ at $4^{\circ} \mathrm{C}$. They were then rinsed in distilled water several times, dehydrated in a gradient series (20-100\%) of ethanol and then in acetone, infiltrated with Epon 812, and finally polymerized in pure Epon 812 for $48 \mathrm{~h}$ at $65^{\circ} \mathrm{C}$. The basolateral amygdala was localized on semi-thin sections. Ultra-thin sections $(70 \mathrm{~nm})$ were cut with a diamond knife and collected on nickel grids. Immune electron microscopy was performed using mouse monoclonal anti-pERK1/2 antibody (Cell Signaling, Beverly, MA, USA) as a primary antibody, and goat anti-mouse IgG colloidal gold particles (5-nm diameter; 1:40 dilution; Boster Biological Technology Ltd., Wuhan, China) as a secondary antibody. In brief, the nickel grid was floated for $5 \mathrm{~min}$ on a drop of TBS-BSA (100 mM Tris-HCl, pH 7.6, $150 \mathrm{mM} \mathrm{NaCl}$ and $2 \%$ bovine serum albumin), then placed on parafilm in a moist chamber. The grid was then floated for 10 min on a drop of $3 \% \mathrm{H}_{2} \mathrm{O}_{2}$, and then washed three times with distilled water and three times with TBS-BSA. The grid was incubated for $20 \mathrm{~min}$ on a drop of $10 \%$ goat serum at room temperature, followed by incubation for $24 \mathrm{~h}$ on a drop of primary antibody solution (diluted 1:100 in TBS-BSA) at $4{ }^{\circ} \mathrm{C}$, and then washed three times. After being incubated for $2 \mathrm{~h}$ on a drop of secondary antibody solution (diluted 1:30 in TBS-BSA) at room temperature, the grid was washed three times with TBS-BSA and once with TBS. Finally, the sections were stained with 5\% aqueous uranyl acetate, and images were captured using an electron microscope (JEM-1200 EX, Japan). The distribution of pERK1/2 protein in the neurons was assessed by observeing the location of the colloidal gold particles.

Brain tissue preparation and immunohistochemical analysis of $p E R K 1 / 2$. Rats in each group $(\mathrm{n}=5)$ were transcardially infused with $200-300 \mathrm{ml}$ of pre-cold saline through the ascending aorta, followed by $300 \mathrm{ml}$ of $4 \%$ pre-cold paraformaldehyde. The whole brains were rapidly removed and dissected on ice, followed by $6-10 \mathrm{~h}$ of post-fixation in $4 \%$ paraformaldehyde at $4{ }^{\circ} \mathrm{C}$. The brain tissue was cut into $15-\mu \mathrm{m}$ thick slices. After treatment with $1 \%$ hydrogen peroxide/methanol, the sections were incubated with $10 \%$ normal goat serum for $30 \mathrm{~min}$ at $37^{\circ} \mathrm{C}$, the primary antibody (mouse monoclonal anti-pERK1/2 antibody, 1:200 dilution; Cell Signaling) at $4^{\circ} \mathrm{C}$ overnight, and the secondary antibody (goat polyclonal anti-mouse IgG, 1:200 dilution; Boster Biological Technology Ltd.) for $1 \mathrm{~h}$ at $37^{\circ} \mathrm{C}$. Then, the sections were incubated with avidinbiotin peroxidase complex (1:200 dilution; Boster Biological Technology Ltd.) for $1 \mathrm{~h}$ at $37^{\circ} \mathrm{C}$ and the immunocomplexes were visualized with $0.05 \%$ DAB.

Images from five slices for each rat were obtained by an independent investigator and the results were analyzed by an image analyzer. The average number of positive cells from the amygdala of each rat, located according to the atlas of Paxinos and Watson (31), was calculated as the average of three sequential brain slices throughout the area of interest and measured in both the left and right hemisphere. The counting of positive cells was performed by an individual blinded to the treatment conditions, using the same magnification and identical color scale setting as a correction for background staining.

Western blotting of pERK1/2. Rats in each group $(\mathrm{n}=5)$ were rapidly decapitated, and the brain was removed and immediately placed in a dish standing on crushed ice. The basolateral amygdala was dissected according to the atlas of Paxinos and Watson (31) using a stereomicroscope, then snap-frozen in liquid nitrogen. Samples from normal control rats and SPS rats were respectively homogenized with a sample buffer containing $200 \mathrm{mM}$ TBS (pH 7.5), 4\% SDS, $20 \%$ glycerol and $10 \%$ 2-mercaptoethanol, and were denatured by boiling for $3 \mathrm{~min}$. The protein fraction (30 $\mu \mathrm{g} / \mathrm{lane})$ prepared from each sample was separated by $12 \%(\mathrm{w} / \mathrm{v})$ gradient sodium dodecyl sulfate (SDS)-polyacrylamide gel electrophoresis (PAGE) and electroblotted onto a PVDF membrane (Millipore, Bedford, MA, USA) from the gel by a semi-dry blotting apparatus (Bio-Rad Laboratories, Inc., Hercules, CA, USA).

The membrane was blocked with 5\% dried skim milk and $0.05 \%$ Tween-20 in TBST at room temperature for $2 \mathrm{~h}$, then incubated with mouse monoclonal anti-pERK1/2 antibody (1:1,000 dilution) overnight at $4^{\circ} \mathrm{C}$.

The blots were washed three times with TBST, incubated with anti-mouse IgG-HRP (1:5,000 dilution; Santa Cruz Biotechnology, Santa Cruz, CA, USA) for $2 \mathrm{~h}$ at room temperature, then washed with TBST. After the incubation, the PVDF membrane was washed three times with TBST before visu- 

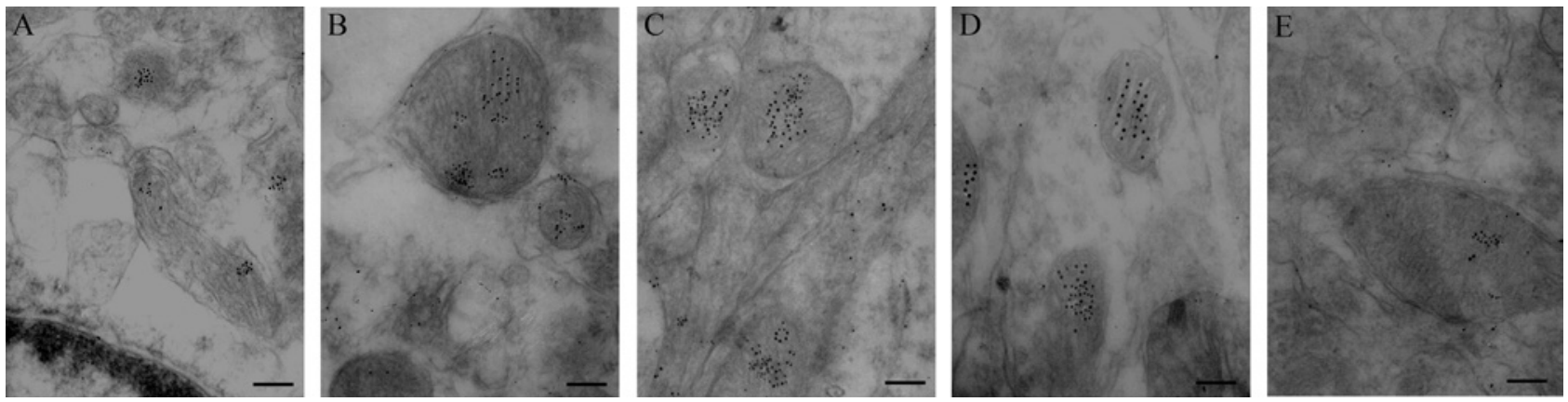

Figure 1. Determination of the distribution of pERK1/2 protein in the amygdala neurons by immune electron microscopy. (A) Control group; (B) SPS 0 min group; (C) SPS 30 min group; (D) SPS 60 min group; (E) SPS 120 min group. Bar, $100 \mu \mathrm{m}$.

alization by enhanced chemiluminescence (ECL; Amersham Pharmacia Biotech, Buckinghamshire, UK). To confirm equal protein loading, the same blots were reincubated with antibodies specific for $\beta$-actin (dilution 1:2,500; Abcam, UK). Immunoreactivity for $\beta$-actin was detected with ECL. The optical density (OD) was analyzed on the Gel Image Analysis System. Each pERK band was normalized with respect to its corresponding $\beta$-actin band, and the values were expressed as the intensity ratio.

Statistical analysis. Values are presented as the means \pm standard error of the means (SEM) and were analyzed using SPSS 11.5 software. Statistical significance was determined by one-way analysis of variance (ANOVA) follwed by the Tukey test when appropriate. Differences with a p-value $<0.05$ were considered statistically significant.

\section{Results}

Immune electron microscopy. The distribution of pERK1/2 protein in the neurons was determined by observing the location of the colloidal gold particles. The results of immune electron microscopy showed that the pERK protein was located in some cell organelles, for example, the mitochondria and neuraxon (Fig. 1). However, the location of pERK1/2 was observed in the cell only, and was not quantitatively analyzed.

Immunohistochemical analysis of pERK1/2. The results of immunohistochemistry are shown in Fig. 2. The pERK1/2 protein was located in cytoplasm, as indicated by brown staining (Fig. 2A-E). In the normal control group, there were few numbers of pERK1/2-positive cells, while in the SPS rats the numbers of positive $\mathrm{pERK} 1 / 2$ cells were significantly increased and peaked at $60 \mathrm{~min}$ after exposure to SPS $(\mathrm{p}<0.01)$ (Fig. 2F).

Western blot analysis of pERK1/2. The Western blotting results of pERK1/2 are shown in Fig. 3. The pERK1/2 proteins were detected in two bands at 42 and $44 \mathrm{kDa}$ (Fig. 3A). The density of the pERK1/2 bands indicated that pERK1/2 was significantly increased in the SPS rats $(0,30,60$ and $120 \mathrm{~min})$ $(\mathrm{p}<0.01)$ and peaked in the SPS 60 min group, exhibiting a 4- to 5 -fold increase compared to the control group $(\mathrm{p}<0.01)$ (Fig. 3B). These results are consistent with those of the immunohistochemical analysis.
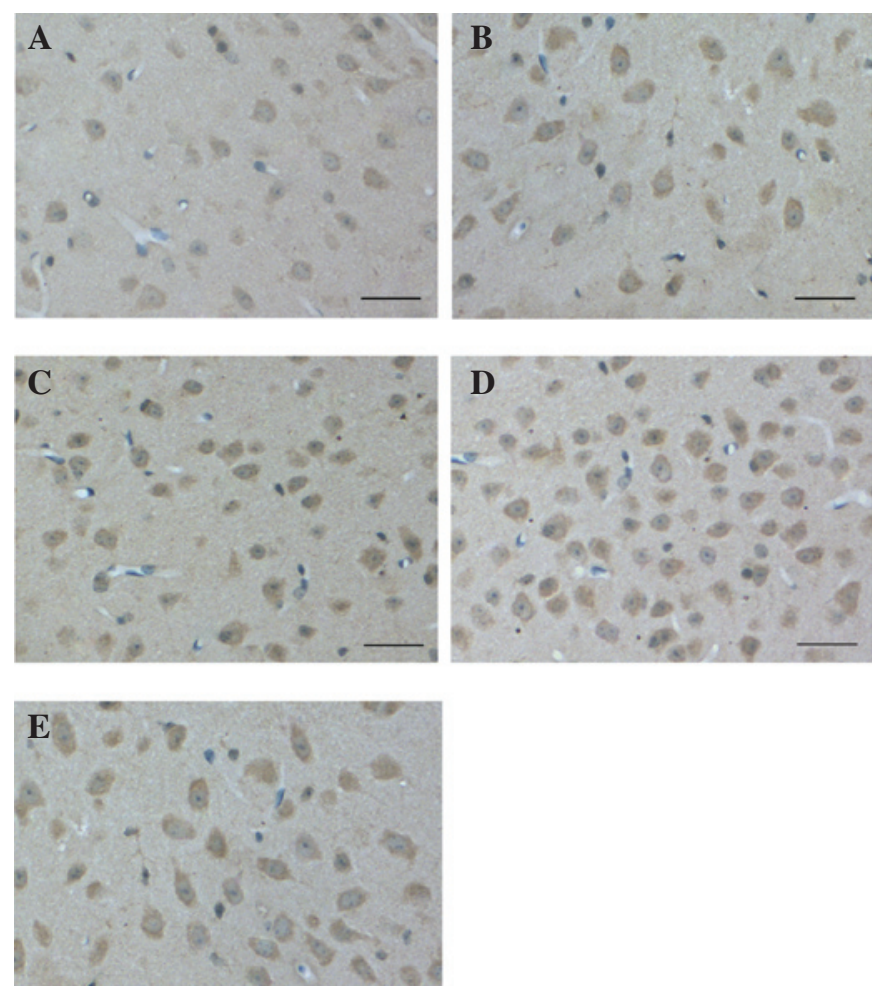

F

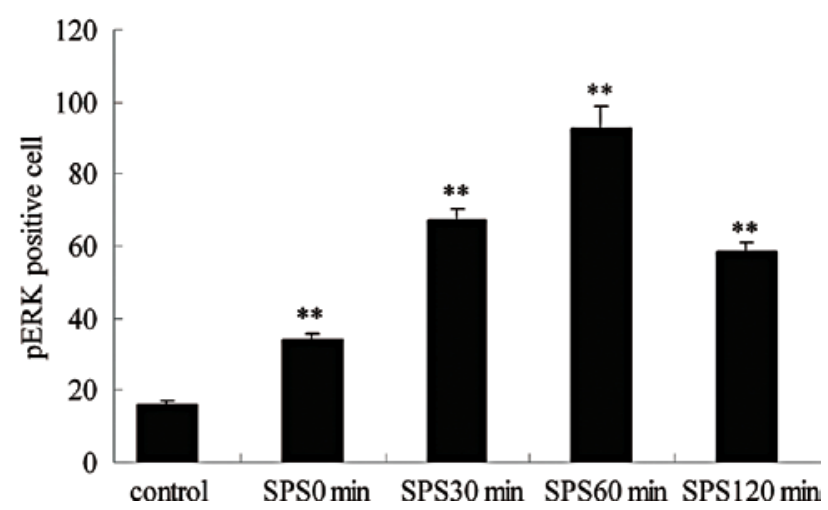

Figure 2. Determination of changes in the pERK1/2 level in the amygdala of SPS rats by immunohistochemical staining. (A-E) Representative photomicrographs of pERK immunostraining. (A) Control group; (B) SPS 0 min group; (C) SPS 30 min group; (D) SPS 60 min group; (E) SPS $120 \mathrm{~min}$ group. Bar, $20 \mu \mathrm{m}$. (F) Quantification of the changes in the number of pERKpositive cells in the amygdala. ${ }^{* *} \mathrm{p}<0.01$ compared to the control group. 
A

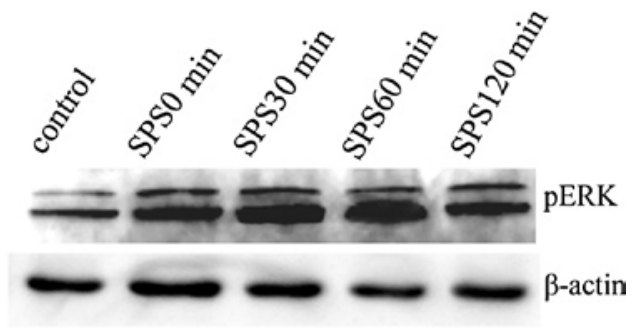

B

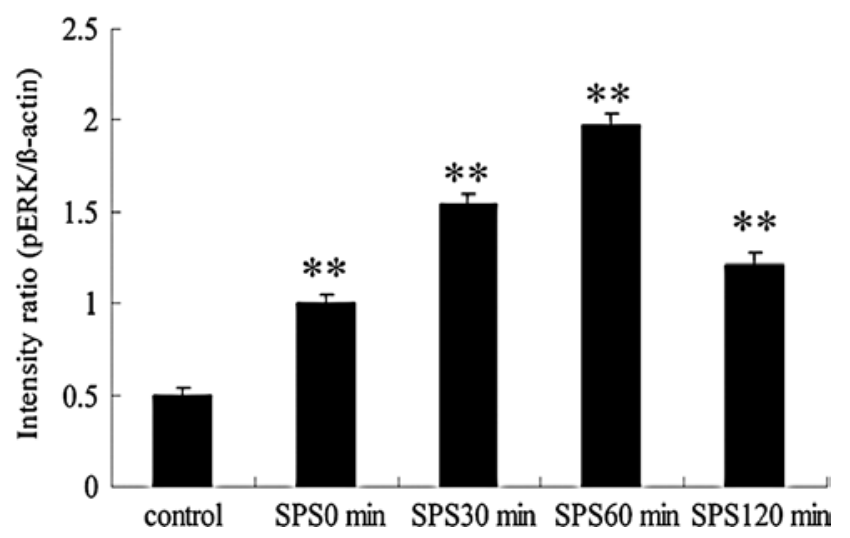

Figure 3. Determination of changes in the pERK1/2 level in the amygdala of normal (control) and SPS rats by Western blotting. (A) Typical results by Western blotting. (B) Relative levels of pERK1/2. Statistical analysis was conducted by one-way ANOVA $\left[\mathrm{F}_{(4,20)}=93.869, \mathrm{p}<0.001\right]$ followed by the Tukey test. ${ }^{* *} \mathrm{p}<0.01$ compared to the control group.

\section{Discussion}

PTSD is defined by symptoms of continuous re-experiencing of the traumatic event, and avoidance of stimuli associated with the trauma and hyperarousal, suggesting a heightened fear response (1). Pathological fear and anxiety may be the manifestation of abnormal modulations in the amygdala and interactions with other regions of the brain, such as the medial prefrontal cortex (mPFC). The amygdala modulates spatial information processing in the hippocampus and is required for the expression of fear (32); indeed, it is the main output center for response to fearful stimuli (33). Neuroimaging studies of PTSD have to date revealed abnormal reductions in mPFC activity $(11,34,35)$, as well as enhanced and distinctive amygdala engagement $(10,14)$, particularly for combat veterans (11). Consequently, this study focused on observing changes in the basolateral nucleus of the amygdala.

The amygdala is divided into three distinct subgroups: the central nucleus, the corticomedial nucleus and the basolateral nucleus (36). The basolateral nucleus is the largest of the three (37), and is the key region for fear initiation. As a result, the basolateral nucleus has been the subject of significant attention. Vyas et al reported that chronic unpredictable stress induces atrophy in the bipolar neurons of the basolateral amygdala (38). Therefore, this study focused on changes in the basolateral nucleus. The ERK pathway, which relays signals from the plasma membrane to the nucleus, is one of the pathways in the mitogen-activated protein kinase signaling system (39). Two ERK proteins (ERK1/2) are components of this signaling pathway.
In this study, we found that the pERK1/2-positive cells in the amygdala were significantly increased in SPS rats, suggesting the involvement of the ERK signal transduction pathway in the response to stress. Studies have shown that the brain serotonergic receptors and norepinephrine levels are increased in the amygdala in response to stress $(40,41)$. ERK hyperphosphorylation induced by stress in the amygdala is likely related to excessive monoaminergic neurotransmitters. ERK activation is a common cellular response to monoamine neurotransmitters, such as 5-hydroxytraptamine, norepinephrine and dopamine (42-44). The molecular mechanism of stress-induced ERK hyperphosphorylation may therefore involve the activation of ERK by neurotransmitters.

In the nervous system, the ERKs are activated in neurons in response to synaptic activity (45). ERK phosphorylation is a key step in mediating cellular responses to various extracellular changes, such as gene expression. In the amygdala, activation of the ERK pathway results in long-term changes in synaptic activity, which are thought to underlie the consolidation of fear memory $(46,47)$. Ailing et al demonstrated that the levels of pERK and c-Fos were significantly increased in the mPFC during anxiety, and that the inhibition of ERK phosphorylation blocked anxiety-induced c-Fos expression. This suggests that the ERK signal transduction pathway plays a crucial role in anxiety, and that the inhibition of the ERK pathway in the mPFC may produce an anxiolysis effect (48). It is therefore of interest to examine which genes are activated by c-Fos induced by SPS in the central nervous system.

In conclusion, we demonstrated that the levels of pERK were significantly increased in the amygdala during SPS. The results suggest that the ERK signal transduction pathway may play a key role in PTSD. At present, the pathogenesis of PTSD is not entirely clear. PTSD may cause a series of biochemical abnormalities and dysfunction in the amygdala, which leads to brain dysfuction. Thus, the pathogenesis of PTSD requires further study.

\section{Acknowledgements}

The authors thank the staff of the China Medical University Experiment Center for their technical support and help in improving the quality of the study. The study was supported by a grant from the National Natural Science Foundation of China (no. 30600341).

\section{References}

1. American Psychiatric Association: Diagnostic and Statistical Manual of Mental Disorders (DSM-IV). 4th edition. American Psychiatric Press, Washington, DC, 1994.

2. Liberzon I, Krstov M and Young EA: Stress-restress: effects on ACTH and fast feedback. Psychoneuroendocrino 22: 443-453, 1997.

3. Stein MB, Yehuda R, Koverola C and Hanna C: Enhanced dexamethasone suppression of plasma cortisol in adult women traumatized by childhood sexual abuse. Biol Psychiatry 42: 680-686, 1997.

4. Yehuda R: Biology of posttraumatic stress disorder. J Clin Psychiatry 62: 41-46, 2001.

5. Yehuda R: Neuroendocrine aspects of PTSD. Handb Exp Pharmacol 169: 371-403, 2005.

6. Khan S and Liberzon I: Topiramate attenuates exaggerated acoustic startle in an animal model of PTSD. Psychopharmacology 172: 225-229, 2004. 
7. Iwamoto $\mathrm{Y}$, Morinobu $\mathrm{S}$, Takahashi $\mathrm{T}$ and Yamawaki $\mathrm{S}$ : Single prolonged stress increases contextual freezing and the expression of glycine transporter 1 and vesicle-associated membrane protein $2 \mathrm{mRNA}$ in the hippocampus of rats. Prog Neuropsychopharmacol Biol Psychiatry 31: 642-651, 2007.

8. McGaugh JL and Cahill L: Interaction of neuromodulatory systems in modulating memory storage. Behav Brain Res 83: 31-38, 1997.

9. LeDoux JE: Emotion: clues from the brain. Ann Rev Psychol 46: 209-235, 1995.

10. Rauch SL, Whalen PJ, Shin LM, McInerney SC, Macklin ML, Lasko NB, Orr SP and Pitman RK: Exaggerated amygdala response to masked facial stimuli in posttraumatic stress disorder: a functional MRI study. Biol Psychiatry 47: 769-776, 2000.

11. Shin LM, Orr SP, Carson MA, et al: Regional cerebral blood flow in the amygdala and medial prefrontal cortex during traumatic imagery in male and female Vietnam veterans with PTSD. Arch Gen Psychiatry 61: 168-176, 2004

12. Shin LM, Wright CI, Cannistraro PA, et al: A functional magnetic resonance imaging study of amygdala and medial prefrontal cortex responses to overtly presented fearful faces in posttraumatic stress disorder. Arch Gen Psychiatry 62: 273-281, 2005.

13. Driessen M, Beblo T, Mertens M, Piefke M, Rullkoetter N, Silva-Saavedra A, Reddemann L, Rau H, Markowitsch HJ, Wulff H, Lange W and Woermann FG: Posttraumatic stress disorder and fMRI activation patterns of traumatic memory in patients with borderline personality disorder. Biol Psychiatry 55: 603-611, 2004

14. Liberzon I, Taylor SF, Amdur R, Jung TD, Chamberlain KR, Minoshima S, Koeppe RA and Fig LM: Brain activation in PTSD in response to trauma-related stimuli. Biol Psychiatry 45: 817-826, 1999.

15. Pissiota A, Frans O, Fernandez M, von Knorring L, Fisher H and Fredrikson M: Neurofunctional correlates of posttraumatic stress disorder: a PET symptom provocation study. Eur Arch Psychiatry Clin Neurosci 252: 68-75, 2002.

16. Protopopescu X, Pan H, Tusecher O, Cloitre M, Goldstein M, Engelien W, Epstein J, Yang Y, Gorman J, LeDoux J, Silbersweig D and Stern E: Differential time courses and specificity of amygdala activity in posttraumatic stress disorder subjects and normal control subjects. Biol Psychiatry 57: 464-473, 2005.

17. Hendler T, Rotshtein P, Yeshurun Y, Weizmann T, Kahn I, Ben-Bashat D, Malach R and Bleich A: Sensing the invisible: differential sensitivity of visual cortex and amygdala to traumatic context. Neuroimage 19: 587-600, 2003

18. Bremner JD, Vermetten E, Schmahl C, Vaccarino V, Vythilingam M, Afzal N, Grillon C and Charney DS: Positron emission tomographic imaging of neural correlates of a fear acquisition and extinction paradigm in women with childhood sexual-abuse-related post-traumatic stress disorder. Psychol Med 35: 791 806, 2005.

19. Willliams LM, Kemp AH, Felmingham K, Barton M, Olivieri G, Peduto A, Gordon E and Bryant RA: Trauma modulates amygdala and medial prefrontal responses to consciously attended fear. Neuroimage 29: 347-357, 2006

20. Cui H, Sakamoto H, Higashi S and Kawata M: Effects of singleprolonged stress on neurons and their afferent inputs in the amygdala. Neuroscience 152: 703-712, 2008.

21. Grewal SS, York RD and Stork PJ: Extracellular-signal-regulated kinase signaling in neurons. Curr Opin Neurobiol 9: 544-553, 1999.

22. Vanhoutte P, Barnier JV, Guibert B, Pages C, Besson MJ, Hipskind RA and Caboche J: Glutamate induces phosphorylation of Elk-1 and CREB, along with c-fos activation, via an extracellular signal-regulated kinase-dependent pathway in brain slices. Mol Cell Biol 19: 136-146, 1999.

23. Sgambato V, Pages C, Rogard M, Besson MJ and Caboche J: Extracellular signal-regulated kinase (ERK) controls immediate early gene induction on corticostriatal stiulation. J Neurosci 18 : 8814-8825, 1998.

24. Hetman M and Gozdz A: Role of extracellular signal regulated kinases 1 and 2 in neuronal survival. Eur $\mathbf{J}$ Biochem 271: 2050-2055, 2004.

25. Sweatt JD: The neuronal MAP kinase cascade: a biochemical signal integration system subserving synaptic plasticity and memory. J Neurochem 76: 1-10, 2007.

26. Gerrits M, Westenbroek C, Koch T, Grootkarzijn A and ter Horst GJ: Increased limbic phosphorylated extracellularregulated kinase 1 and 2 expression after chronic stress is reduced by cyclic 17 beta-estradiol administration. Neuroscience 142 : $1293-1302,2006$.
27. Campos-Gonzalez R and Kindy MS: Tyrosine phosphorylation of microtubule-associated protein kinase after transient ischemia in the gerbil brain. J Neurochem 59: 1955-1958, 1992.

28. Kindy MS: Inhibition of tyrosine phosphorylation prevents delayed neuronal death following cerebral ischemia. J Cereb Blood Flow Metab 13: 372-377, 1993.

29. Rundén E, Seglen PO, Haug FM, Ottersen OP, Wieloch T, Shamloo M and Laake JH: Regional selective neuronal degeneration after protein phosphatase inhibition in hippocampal slice cultures: evidence for a MAP kinase-dependent mechanism. J Neurosci 18: 7296-7305, 1998.

30. Ding JL, Han F and Shi YX: Single-prolonged stress induces apoptosis in the amygdala in a rat model of post-traumatic stress disorder. J Psychiatr Res 44: 48-55, 2010.

31. Paxinos $G$ and Watson C: The Rat Brain in Stereotaxic Coordinates. 4th edition. Academic Press, 1998.

32. Garcia R, Vouimba RM, Baudry M and Thompson RF: The amygdala modulates prefrontal cortex activity relative to conditioned fear. Nature 402: 294-296, 1999.

33. Charney DS: Psychobiological mechanisms of resilience and vulnerability: implications for successful adaptation to extreme stress. Am J Psychiatry 161: 195-216, 2004.

34. Bremner JD, Staib LH, Kaloupek D, Southwick SM, Soufer R and Charney DS: Neural correlates of exposure to traumatic pictures and sound in Vietnam combat veterans with and without posttraumatic stress disorder: a positron emission tomography study. Biol Psychiatry 45: 806-816, 1999.

35. Shin LM, McNally RJ, Kosslyn SM, Thompson WL, Rauch SL, Alpert NM, Metzqer LJ, Lasko NB, Orr SP and Pitman RK: Regional cerebral blood flow during scriptdriven imagery in childhood sexual abuse-related PTSD: a PET investigation. Am J Psychiatry 156: 575-584, 1999.

36. Harding AJ, Stimson E, Henderson JM and Halliday GM: Clinical correlates of selective pathology in the amygdala of patients with Parkinson's disease. Brain 125: 2431-2445, 2002.

37. Sims KS and Williams RS: The human amygdaloid complex: a cytologic and histochemical atlas using Nissl, myelin, acetylcholinesterase and nicotinamide adenine dinucleotide phosphate diaphorase staining. Neuroscience 36: 449-472, 1990.

38. Vyas A, Mitra R, Shankaranarayana Rao BS and Chattarji S: Chronic stress induces contrasting patterns of dendritic remodeling in hippocampal and amygdaloid neurons. J Neurosci 22: 6810-6818, 2002

39. Lewis TS, Shaapiro PS and Ahn NG: Signal transduction through MAP kinase cascades. Adv Cancer Res 74: 49-139, 1998.

40. Compaan JC, Groenink L, van der Gugten J, Maes RA and Olivier B: 5-HT1A receptor agonist flesinoxan enhances Fos immunoreactivity in rat centralamygdala, bed nucleus stria terminalis and hypothalamus. Eur J Neurosci 8: 2340-2347, 1996.

41. Cecchi M, Khoshbouei H and Morilak DA: Modulatory effects of norepinephrine, acting on alpha 1 receptors in the central nucleus of the amygdala, on behavioral and neuroendocrine responses to acute immobilization stress. Neuropharmacology 43: 1139 1147, 2002.

42. Graeff FG, Guimarães FS, De Andrade TG and Deakin JF: Role of 5-HT in stress, anxiety, and depression. Pharmacol Biochem Behav 54: 129-141, 1996.

43. Johnson MR and Lydiard RB: The neurobiology of anxiety disorders. Psychiatr Clin North Am 18: 681-725, 1995.

44. Ressler KJ and Nemeroff CB: Role of serotonergic and noradrenergic systems in the pathophysiology of depression and anxiety disorders. Depress and Anxiety 12: 2-19, 2000.

45. Davis $S$ and Laroche S: Mitogen-activated protein kinase/extracellular regulated kinase signalling and memory stabilization: a review. Genes Brain Behav 5: 61-72, 2006.

46. Schafe GE and LeDoux JE: Memory consolidation of auditory Pavlovian fear conditioning requires protein synthesis and protein kinase A in the amygdala. J Neurosci 20: RC96, 2000.

47. Rodrigues SM, Schafe GE and LeDoux JE: Molecular mechanisms underlying emotional learning and memory in the lateral amygdala. Neuron 44: 75-91, 2004

48. Ailing F, Fan L, Li S and Manji S: Role of extracellular signalregulated kinase signal transduction pathway in anxiety. J Psychiat Res 43: 55-63, 2008. 